\title{
Integrated medical care in a mental health clinic improved quality of care and outcomes in serious mental disorders
}

\author{
Druss BG, Rohrbaugh RM, Levinson CM, et al. Integrated medical care for patients with serious psychiatric illness: a \\ randomised trial. Arch Gen Psychiatry 2001 Sep;58:861-8.
}

Sources of funding: in part, VA Connecticut Mental Illness

Research, Education, and Clinical Center and the National Institute of Mental Health.

For correspondence: Dr B G Druss, Yale University, New Haven CT, USA.

Benjamin.druss@ yale.edu

Integrated medical care $v$ usual care for improving access to medical care $\dagger$

\begin{tabular}{|c|c|c|c|c|}
\hline Outcomes at 1 year & $\begin{array}{l}\text { Integrated } \\
\text { care }\end{array}$ & $\begin{array}{l}\text { Usual } \\
\text { care }\end{array}$ & $\mathrm{RBI}(95 \% \mathrm{Cl})$ & NNT (Cl) \\
\hline \multirow[t]{2}{*}{ Primary care visits } & $92 \%$ & $72 \%$ & 27 (7 to 55$)$ & $6(4$ to 18$)$ \\
\hline & & & $\operatorname{RRR}(\mathrm{Cl})$ & NNT (CI) \\
\hline Emergency department visits & $12 \%$ & $26 \%$ & $55 \%(1$ to 80$)$ & 7 (4 to 436$)$ \\
\hline
\end{tabular}

tAbbreviations defined in glossary; RBI, RRR, NNT, and $\mathrm{Cl}$ calculated from data in article.

\section{COMMENTARY}

It is well established that patients with chronic mental illness have high rates of physical illness and excess mortality. ${ }^{1-3}$ Causes of the excess morbidity and mortality include lifestyle (smoking, substance abuse, and obesity), medication side effects, and difficulty accessing care. ${ }^{12}$ Several suggestions have been made for improving the health care of patients with chronic psychiatric illnesses, including training psychiatrists to become primary care providers. ${ }^{4}$

Little research has been done on interventions to improve the health status of chronic psychiatric patients. Thus, this study by Druss $e t$ al is an important contribution to the literature. 1 limitation of the study is that only $67 \%$ of the patients completed all 3 health status surveys (baseline, 6 mo, and 12 mo), making the differences in physical health status somewhat questionable. An additional limitation is that the size and duration of follow up of the study did not allow an effect on mortality or other important adverse health outcomes to be shown.

Although the study by Druss et al is important in showing that integrated care improves access to needed primary care services in a chronically mentally ill population, it may be difficult to apply this model in other settings. In the US, care for the chronically mentally ill is often provided by public mental health clinics which are located apart from primary care clinics and are funded or operated by separate government agencies. In the private sector in the US, funding mechanisms also make integration difficult. ${ }^{5}$ Thus, a major challenge is to overcome organisational barriers that impede the provision of better integrated care for the mentally ill.

Gregory E Gray, $\mathrm{MD}, \mathrm{PhD}$ Charles R Drew University of Medicine and Science Los Angeles, California, USA

1 Phelan M, Stradins L, Morrison S. Physical health of people with severe mental illness. BMJ 2001;322:443-4.

2 Osborn DPJ. The poor physical health of people with mental illness. West J Med 2001:175:329-32.

3 Felker B, Yazel JJ, Short D. Mortality and medical comorbidity among psychiatric patients: a review. Psychiatr Serv 1996;47:1356-63.

4 Silberman EK. Should we train psychiatrists as primary care providers? Psychosomatics 1999;40:126-9

5 Goldberg RJ. Financial incentives influencing the integration of mental health care and primary care. Psychiatr Serv 1999;50:1071-5.

\section{Patients}

120 patients (mean age 45 y, 99\% men) who had serious mental disorders and would benefit from primary care. Exclusion criteria included having a current primary care provider, urgent or multiple serious chronic problems, and medical hospital admissions in the past 6 months. Follow up was 100\% for service use, quality of preventive care, and costs; random regression was used to account for missing health status data.

\section{Intervention}

59 patients were allocated to integrated care and 61 to usual care. For integrated care, clinic staff emphasised patient education, preventive services, and close contact with mental health care providers. Patients also received telephone reminders before appointments, and whenever possible, clinical appointments were scheduled immediately after mental health visits. When appointments were missed, clinic staff made active efforts to reschedule visits. Patients in the usual care group were assigned to a primary care provider.

\section{Main outcome measures}

Service use (medical and psychiatric visits), quality of preventive care (17 preventive measures), physical (physical component summary of the 36 Item Short Form Health Survey) and mental health status (Symptom Checklist 90 and Addiction Severity Index), and costs in US\$.

\section{Main results}

Analysis was by intention to treat. More patients in the integrated care group than the usual care group made primary care visits $(\mathrm{p}=0.006)$ (table) and received 15 of 17 preventive measures at 1 year (all $\mathrm{p}$ values $<0.05$ ). Fewer patients in the integrated care group than the usual care group made emergency department visits at 1 year $(p=0.04)$ (table). Improvement in physical health status over 1 year was greater in the integrated care group than the usual care group (mean change from baseline score $4.7 v-0.3, \mathrm{p}<0.001)$. Primary care costs per patient were greater in the integrated care group than the usual care group (US\$1582 v\$398, $\mathrm{p}=0.02$ ), but total healthcare costs did not differ.

\section{Conclusion}

In patients with serious mental disorders, integrated medical care given in a mental health clinic was better than usual care in a general medicine clinic for improving access to primary care services, quality of preventive care, and health related quality of life.

*See glossary. 